\title{
Comparison of the crushing performance of hollow and foam-filled small-scale composite tubes with different geometrical shapes for use in sacrificial cladding structures
}

\author{
Sivakumar Palanivelu ${ }^{1 *}$, Wim Van Paepegem ${ }^{1}$, Joris Degrieck ${ }^{1}$, John Vantomme ${ }^{2}$, Dimitrios Kakogiannis ${ }^{3}$, \\ Johan Van Ackeren ${ }^{3}$, Danny Van Hemelrijck ${ }^{3}$, Jan Wastiels ${ }^{3}$ \\ ${ }^{1}$ Department of Materials Science and Engineering, Ghent University, Sint-Pietersnieuwstraat 41, 9000 Gent, \\ Belgium \\ ${ }^{2}$ Royal Military Academy, Civil and Materials Engineering Department, Building G, Level 0, 8 Av. Hobbema \\ B-1000, Brussels, Belgium \\ ${ }^{3}$ Department of Mechanics of Materials and Constructions, Vrije Universiteit Brussel, Pleinlaan 2 B-1050 \\ Brussels, Belgium
}

\begin{abstract}
This paper presents the quasi-static crushing performance of nine different geometrical shapes of smallscale glass/polyester composite tubes filled with polyurethane closed-cell foam for use in sacrificial cladding structures. The effect of polyurethane foam on the crushing characteristics and the corresponding energy absorption is addressed for each geometrical shape of the composite tube. Composite tubes with two different thicknesses ( $1 \mathrm{~mm}$ and $2 \mathrm{~mm}$ ) have been considered to study the influence of polyurethane foam on the crushing performance. From the present study, it was found that the presence of polyurethane foam inside the composite tubes suppressed the circumferential delamination process and fibre fracturing; consequently, it reduced the specific energy absorption of composite tubes. Furthermore, the polyurethane foam attributed to a higher peak crush load for each composite tube. However, the presence of polyurethane foam inside the composite tubes significantly increased the stability of the crushing phenomena especially for the square and hexagonal cross sectional composite tubes with $1 \mathrm{~mm}$ wall thickness. The results from this study are compared with our previous results for composite tubes without polyurethane foam [1].
\end{abstract}

KEYWORDS: A: Glass fibres; A: Foams; B: Delamination; D: Mechanical testing

\section{Introduction}

The increasing terrorist activities throughout the world riveted our attention to safeguard human beings and civil engineering structures from explosion. Catastrophic failure of main load bearing members of civil engineering structures during explosion causes major human casualties. Hence, a preventive solution is needed to safeguard the civil engineering structures and to avoid human casualties. Considerable efforts have been taken by the research community to propose suitable solutions for this problem. Out of many proposed solutions, the concept of sacrificial cladding structure design has attracted more attention in terms of its functionality and its predictable behaviour. Any sacrificial cladding structure can have two layers (an outer skin and an inner core). The function of the outer skin is to distribute the blast pressure more evenly to the inner core which deforms progressively and alters a high force, short duration impulse from the blast to a low load, long duration impulse to the structure upon which it is mounted. In order to achieve that, the failure load of the sacrificial cladding inner core structure should be kept as low as possible. Keeping a lower failure load for the inner core may attribute to achieve progressive deformation during an explosion event and so the transferred peak force to the non-sacrificial structure can be minimised. A few researchers [2, 3] have investigated metals and its alloys for both outer skin and inner core. However, these materials are not feasible in terms of cost, weight and maintenance. Due to superior specific energy absorption properties, composite materials have been studied and accepted for many applications [4-8]. Hence, we propose composite tubes for the inner core of the sacrificial cladding structure. The concept of the proposed sacrificial cladding structure and the proposed materials for the inner core and the outer skin can be found from ref [1]. In

*Corresponding author: Sivakumar Palanivelu, Tel: +32-(0)9-264.33.15, Fax: +32-(0)9-264.35.87 
order to alter the impulse from the blast to the structure upon which it is mounted, the inner core members have to be designed for a controlled progressive crushing and with a higher energy absorption. For that, the different variables which can alter the energy absorption of composite tubes have to be understood.

With regard to the above requirements our previous study [1] was focused on the effect of geometry and the corresponding dimensions on the energy absorption of nine different geometrical shapes of hollow composite tubes. To achieve the progressive crushing failure modes the t/D ratio of these tubes was chosen as per the recommendation given in ref [9]. These tubes were manufactured by hand lay-up technique using unidirectional E-glass fabric, polyester resin and polyurethane foam mandrels. The scatter in the crushing parameters was very low, despite using hand lay-up technique for manufacturing these composite tubes [1]. After manufacturing of these composite tubes, the polyurethane foam inside each composite tube was removed manually by using special tools which is a time consuming task. Leaving the polyurethane foam inside the composite tube can save considerable quantity of time; furthermore, the additional mass due to the polyurethane foam inside the composite tubes is negligible compared to the mass of the hollow composite tubes. In addition to that, during our previous study a few geometrical shapes of the composite tubes (square and hexagonal cross sectional tube with $1 \mathrm{~mm}$ wall thickness) without polyurethane foam exhibited catastrophic and non-uniform crushing failure modes [1]. The effect of polyurethane foam on the stability of the crushing process is unknown for such geometrical shapes (with unidirectional fibre orientation) of the composite tubes. Furthermore, a comparison of results with our previous study [1] can conclude whether or not to use composite tubes with polyurethane foam for the inner core of the proposed sacrificial cladding structure. Therefore, it is worth to investigate the effect of polyurethane foam on the crushing performance of these tubes.

Many studies [10-14] have been conducted to study the effect of metallic and nonmetallic foams on the energy absorption of thin-walled metal tubes. The general conclusion of these researches is that the number of folds formed in foam-filled tubes increased with foam filling and also with increasing foam filler density. As a result, the energy absorption of foam-filled tubes was higher than the sum of the energy absorption of the empty tube and the filler. Furthermore, the interaction of tube wall and foam resulted into an axisymmetric mode (concertina) of deformation. In contrast to the metal tubes, Very few studies [15-18] have been conducted on composite tubes with foam-filler material. Guden et al. [16] studied the effect of aluminium closed-cell foam filling on the quasi-static crushing behaviour of E-glass woven fabric polyester composite tubes and thin-walled aluminium/glass polyester composite hybrid tubes. They concluded that the foam filling of hybrid tubes resulted into an axial splitting of the outer composite tubes due to the resistance imposed by the aluminium tube. Babbage and Malick [15] investigated the quasi-static crushing behaviour of epoxy foamfilled aluminum tubes overwrapped with filament-wound E-glass/epoxy composite layers. The conclusion of that research was that the overwrap increased the performance (peak crush load, mean crush load and the corresponding energy absorption) of the square and circular cross sectional tubes. Harte et al. [17] investigated the energy absorption behaviour of foamfilled (polyurethane foam and polymethyl-acrylamid foam) circular cross sectional braided composite tubes. In this work, an analytical model for energy absorption calculation is proposed considering the progressive failure collapse by axisymmetric buckling. Mamalis et al. [18] studied the crushing performance of aluminium and polyurethane foam-filled square cross-sectional glass/vinylester composite tubes. The square tube filled with polyurethane

*Corresponding author: Sivakumar Palanivelu, Tel: +32-(0)9-264.33.15, Fax: +32-(0)9-264.35.87 
foam exhibited a brittle peripheral rupture, followed by the penetration of the lower part into the upper part which resulted into a lower energy absorption value. However, the tube filled with aluminium foam showed progressive crushing failure modes (delamination, axial cracks, bending of lay-ups and fibre fracturing) which resulted into a higher energy absorption value.

In order to understand the crushing behaviour and the corresponding energy absorption of the small-scale composite tubes with polyurethane foam, quasi-static axial crushing tests were conducted. The dimensional, material and architectural parameters of the composite tubes are the same as in our previous study [1]. The details of the adopted geometrical shapes and the corresponding dimensions for $1 \mathrm{~mm}$ thickness tubes with polyurethane foam are given in Figure 1(a). From the quasi-static tests, parameters such as the specific energy absorption, peak crush load, mean crush load and the efficiency of the crushing process are presented.

\section{Experimental testing and results}

The small-scale composite tubes tested in this investigation were fabricated by hand lay-up using a uni-directional E-glass fabric (Roviglass R475/17), Synolite 1408-P-1 polyester resin and polyurethane foam with density of $104 \mathrm{~kg} / \mathrm{m}^{3}$ (closed-cell $>90 \%$ of volume). The steps involved in manufacturing of these composite tubes and the corresponding post curing details can be found in ref [1]. To induce the progressive crushing a triggering geometry ( $45^{\circ}$ chamfering) was introduced on one side of the composite tubes only (refer Figure 1(b)). Totally, 19 composite tube series were tried out to study the deformation patterns and the corresponding energy absorption behaviour. The nomenclature and the corresponding dimensional details of the composite tube series are given in Table 1 . The average linear density (mass per unit length) measured from four tubes for each composite tube series is reported in Table 1.

An electro-mechanical Instron 4505 machine with $10 \mathrm{~mm} / \mathrm{min}$ cross head displacement was used for conducting all the quasi-static crushing tests. For simplification, the compressive parameters (load, deformation, stress and strain) are indicated in positive numbers. For each composite tube series a minimum of four tests has been conducted and the average of all the four tests has been taken into account to calculate the crushing parameters of the composite tubes. To discuss the typical load-deformation behaviour of the composite tubes a representative measurement from each composite tube series is presented. In order to measure the compressive behaviour of the polyurethane foam uni-axial compressive tests have been conducted on polyurethane foam as per ASTM 1621-91 (refer Figure 2). The figure shows the typical elasto-plastic behaviour with the linear elastic regime, the plateau regime and the densification regime.

\subsection{Square cross sectional tubes with polyurethane foam}

The deformation patterns of polyurethane foam-filled square cross sectional composite tubes with $1 \mathrm{~mm}$ thickness are shown in Figure 3(a - top) and 3(b -top). These composite tubes exhibited progressive failure modes. After the crushing of the triggering profile major longitudinal cracks (axial cracks) were observed at the corners of the tube. This is due to the stress concentrations at those locations [7, 19]. The axial cracks were formed only at the interface locations of one roving to another (Figure 3(a - top)). Simultaneously, the

*Corresponding author: Sivakumar Palanivelu, Tel: +32-(0)9-264.33.15, Fax: +32-(0)9-264.35.87 
polyurethane foam inside the composite tube was subjected to compression. Subsequently, the interface between the polyurethane foam and the composite tube walls was subjected to compressive shear failure. As a result, thin layers of polyurethane foam stayed on the inner surface of each composite wall segment (Figure 3(a)). The major crushing energy of the composite tubes was consumed by lamina bending followed by the breakage of resin bonds. Before reaching the densification regime, the polyurethane foam was loaded in pure compression. The longitudinal cut section of these tubes confirmed the same. However, after reaching about $60 \mathrm{~mm}$ of deformation length the polyurethane foam showed a compressive shear failure mode. The load-deformation history of these composite tubes showed three phases (Figure 3(b - top)). The first phase corresponds to the crushing of the triggering profile, simultaneous compression of polyurethane foam and initiation of axial cracks. During the second phase due to the propagation of axial cracks the load decreased abruptly. At the end of this second stage a significant amount of the energy was consumed by friction, bending of the petals and the breakage of resin bonds. These failure modes continued for the subsequent stages of crushing and hence, the load of the tube oscillated around a mean value; this was the third stage of the crushing. The average peak crush load (from 4 test specimens) for this case was $4.24 \mathrm{kN}$. The presence of polyurethane foam increased the performance of the tubes significantly. Our previous study [1] on $1 \mathrm{~mm}$ thickness square cross sectional composite tubes without polyurethane foam showed a catastrophic failure mode. This shows the strengthening and the stability effect of polyurethane foam on the crushing performance of square cross-sectional composite tubes. For these tubes there was no clear evidence of circumferential delamination during the crushing of the triggering profiles.

Similar to the $1 \mathrm{~mm}$ thickness tubes, the polyurethane foam-filled $2 \mathrm{~mm}$ thickness square cross-sectional composite tubes showed uniform and progressive crushing failure modes throughout their length (Figure 3(a - bottom) and 3(b - bottom)). The initial crushing stages of these tubes showed a clear evidence of circumferential delamination at the mid thickness of the tubes. However, the delamination did not continue for later crushing stages. After the initial circumferential delamination, due to stress concentrations the primary axial cracks developed along the corners. As a result, each side of the composite tube wall has split into petals moving inwards and outwards [5, 20, 21]. However, the polyurethane foam prevented the flow of inner petals towards the axis of the tube. As a result, further delamination was suppressed. Due to the above phenomenon all the petals started to move outwards (away from the tube axis). This failure mode is different from what has been reported in [18]. The mean crush load and the corresponding energy absorption of this case (SDF) was considerably lower than from our previous results [1]. The reason for the lower energy absorption was the absence of continuous delamination followed by fibre fracturing. The average peak crush load for this case was $9.05 \mathrm{kN}$ which is slightly higher than the case of composite tubes without polyurethane foam [1].

\subsection{Circular cross sectional tubes with polyurethane foam}

The typical progressive deformation pattern and the corresponding load-deformation curve for $1 \mathrm{~mm}$ thickness circular cross sectional composite tubes filled with polyurethane foam are shown in Figure 4(a - top) and 4(b - top). These tubes showed a clear evidence of delamination at the triggering location. Furthermore, the number of axial cracks for this case was higher than for the square cross sectional tubes. The uniform geometry of the circular cross sectional tube facilitated a large number of axial cracks (varied from 10 to 13) and thus more petals were formed [19, 22]. The major amount of the crushing energy was absorbed by

*Corresponding author: Sivakumar Palanivelu, Tel: +32-(0)9-264.33.15, Fax: +32-(0)9-264.35.87

Email: Sivakumar.Palanivelu@UGent.be 
the increasing number of longitudinal cracks and the subsequent bending of petals [21]. Due to the resistance of the polyurethane foam the delamination was suppressed immediately after crushing of the triggering profile. As a result all petals started to bend outwards and consequently, no fibre fracturing was observed. The average peak crush load of this case (CSF) was $4.78 \mathrm{kN}$ which was higher than the case of tubes without polyurethane foam [1]. The progressive deformation patterns and the failure modes of CDF tubes were very similar to CSF tubes (refer Figure 4(a - bottom) and 4(b - bottom)). The number of axial cracks for this case varied from 8 to 10 for each composite tube. The average peak crush load of this case (CDF) was $7.82 \mathrm{kN}$.

\subsection{Hexagonal cross sectional tubes with polyurethane foam}

The crushing performance of $1 \mathrm{~mm}$ thickness hexagonal cross-sectional composite tubes (HSF) with polyurethane foam was very similar to the case of $1 \mathrm{~mm}$ thickness square cross-sectional composite tubes (SSF). However, these tubes showed a clear evidence of delaminations at the triggering locations similar to the $1 \mathrm{~mm}$ thickness circular crosssectional tubes. The axial cracks occurred only at the corner locations of the tube (refer Figure 5(a)). This result is different from our previous study [1]. The hexagonal composite tubes (1 mm thickness) without polyurethane foam exhibited a catastrophic failure mode and the location of axial cracks at the corners was not consistent [1]. The presence of polyurethane foam inside the composite tube increased the stability of the composite tube walls and controlled the failure process significantly (refer Figure 5(b - top)). The average peak crush load of these composite tubes is $3.51 \mathrm{kN}$. The progressive deformation patterns (axial cracks, lamina bending and foam compression) of the $2 \mathrm{~mm}$ thick hexagonal cross sectional composite tubes are shown in Figure 5(a - bottom) and 5(b - bottom). Similar to the $1 \mathrm{~mm}$ thickness tubes (HSF) the number of axial cracks for this case (HDF) was limited to six. The average peak crush load of this case was $8.88 \mathrm{kN}$.

\subsection{Hourglass type - A shaped (circular cross-sectional) tubes with polyurethane foam}

The progressive crushing behaviour of the hourglass type - A shaped composite tubes with polyurethane foam (HASF and HADF) was very similar to the circular cross sectional composite tubes (refer Figure 6(a)). A considerable amount of compressive shear failure of the polyurethane foam occurred at the plane B which is indicated in Figure 6(b - top). This was due to the composite tube geometry. The reduced cross section from plane A to B directed the polyurethane foam compression at an angle of $10^{\circ}$ (Figure $1(\mathrm{a})$ ). Due to a lower thickness of the polyurethane foam from plane B to $\mathrm{C}$ and the subsequent compression of foam from the top end of the tube a significant amount of compressive shear failure was noticed at location plane $B$. The sectional cut of these tubes confirmed the same. Furthermore, the failed polyurethane foam was accumulated and subjected to compression at the mid-length of the composite tube (due to a reduced cross section from plane B to C). Because of this process, the crush load of this composite tube increased considerably after achieving $50 \mathrm{~mm}$ of deformation length (Figure 6(b)). The average peak crush load was 3.79 $\mathrm{kN}$ and $8.91 \mathrm{kN}$ for HASF and HADF tubes respectively. 


\subsection{Hourglass type - B shaped (circular cross-sectional) tubes with polyurethane foam}

The deformation patterns of the hourglass type - B shaped composite tubes (HBSF and HBDF) are shown in Figure 7(a) and 7(b). For these tubes a significant amount of polyurethane foam was blocked at the mid length of the tube. The reduced cross section of the tube attributed to this blockage. This evidence can be noticed from Figure 7(b); the crush load increased significantly after $50 \mathrm{~mm}$ of deformation length. The average peak crush load was $3.94 \mathrm{kN}$ and $7.15 \mathrm{kN}$ for HBSF and HBDF tubes respectively. Similar to other composite tube series, due to the absence of continuous delamination there was no fibre fracturing observed.

\subsection{Hourglass type - X shaped (circular cross-sectional) tubes with polyurethane foam}

The initial crushing stages of HXSF and HXDF tubes showed the progressive crushing of the triggering profile followed by formation of axial cracks (Figure 8(a) and 8(b)). The number of axial cracks (6 to 8) was higher than for the case without polyurethane foam [1]. The additional stability of polyurethane foam might have attributed to this increased number of axial cracks. In later stages, the fibres at the minor diameter location were pulled towards the axis of the tube due to a lower thickness of the polyurethane foam (at the minor diameter locations) and the geometrical shape of the tube. As a result, each composite wall segment underwent a local wall buckling mode (Figure 8(b)). At this stage a significant increase in crush load was noticed (Figure 8(b). Subsequently, the fibres (at the major diameter location) were subjected to fracturing due to higher radial shear stresses (refer Figure 8(b). Due to this phenomenon a considerable amount of polyurethane foam shearing was observed. This sequence of failures continued to the next major diameter region of the composite tubes. The load-deformation histories of these composite tubes showed lower peak crush loads ( $2.39 \mathrm{kN}$ and $4.81 \mathrm{kN}$ for HXSF and HXDF respectively).

\subsection{Hourglass type - Y shaped (circular cross-sectional) tubes with polyurethane foam}

The crushing performance of the hourglass type - Y shaped composite tubes (HYSF and HYDF) filled with polyurethane foam was very similar to the hourglass type - X geometry tubes (refer Figure 9(a) and 9(b)). Due to the tube geometry (no alignment of triggering profiles to the direction of the compressive loading), there was no initial delamination failure mode observed for these composite tubes. The peak crush load of these composite tubes corresponds to the formation of axial cracks at the major diameter regions and polyurethane foam compression. The average peak crush load for these composite tubes was $1.40 \mathrm{kN}$ and $3.51 \mathrm{kN}$ for HYSF and HYDF composite tubes respectively.

\subsection{Conical circular type - X tubes with polyurethane foam}

The crushing performance of these composite tubes (CXSF and CXDF) was similar to the circular cross-sectional composite tubes (CSF and CDF). The final deformation patterns and the corresponding sequential failure stages are shown in Figure 10(a) and 10(b). For a few composite tubes (both CXSF and CXDF) due to the gradual reduction in cross section towards the bottom side and the subsequent compression of polyurethane foam, the tubes split into two halves (Figure 10(a - top)). This may be due to a lower hoop stress of the tube at the reduced cross section and subsequent compression of polyurethane foam. However,

*Corresponding author: Sivakumar Palanivelu, Tel: +32-(0)9-264.33.15, Fax: +32-(0)9-264.35.87 
this phenomenon occurred at the end of the crushing and hence, there was no significant effect on the load-deformation curve observed. The average peak crush loads were $4.15 \mathrm{kN}$ and $10.6 \mathrm{kN}$ for CXSF and CXDF composite tubes respectively.

\subsection{Conical circular type - Y tubes with polyurethane foam}

The progressive deformation patterns and the corresponding load-deformation curves of CYSF and CYDF composite tube series are shown in Figure 11(a) and 11(b). For these tubes, during the crushing of the triggering profiles a clear evidence of delamination was noticed. For all CYDF tubes, the load was reduced suddenly after the peak crush load. The reduced crush load corresponded to the formation and propagation of axial cracks. This may be due to the combined effect of a higher t/D ratio (0.092) of the composite tube and a lower thickness of polyurethane foam at the triggering locations. The number of axial cracks varied from 8 to 12 for each case.

\subsection{Circular cross-sectional tubes with partially removed polyurethane foam}

As we have seen earlier, the delamination process was suppressed by the polyurethane foam for all tube series. Hence, an experiment was made to study the effect of foam length on the delamination process. The idea is to allow the delamination failure for certain length and then to study the effect of polyurethane foam on the deformation pattern. The circular cross sectional tube with $2 \mathrm{~mm}$ thickness was chosen for this study; subsequently, the polyurethane foam at the crushing side was removed for 3 different lengths $(10 \mathrm{~mm}, 20 \mathrm{~mm}$ and $30 \mathrm{~mm})$. Although al three test cases were conducted (refer Figure 12(a - top)) only one case (30 mm of foam removal) is discussed here due to the similarity of the results. The results of these tests showed the circumferential central delamination (which split the wall thickness into two halves), axial cracks, lamina bending and fibre fracturing failure modes. However, the delamination failure mode was suppressed when the crushing length reached the polyurethane foam similar to earlier cases. As an example, the final deformation pattern of one of the tubes is presented in Figure 12(a - bottom). The corresponding load-deformation curve also shows the similar evidence (refer Figure 12(b)). The mean crush load of this tube was reduced significantly after reaching $30 \mathrm{~mm}$ of deformation length.

\section{Comparison of performance parameters}

A comparison of the crushing parameters of different geometrical shapes of the composite tubes filled with polyurethane foam is presented in this section. When characterizing the energy absorption capacity of a material or structure the following three important parameters have to be considered [5, 23]. The first parameter is the mean load ( $P_{\text {mean }}$ - can be calculated using Equation 1); it is a measure of average force required to deform the material in a progressive manner. The second important parameter is the specific energy absorption (SEA - energy absorbed per unit mass of the crushed material) which provides a measure of the energy absorption ability of a structural component (Equation 2). The third parameter crush efficiency $\left(\eta_{c}\right)$ gives an idea about how ideal a structural component for energy absorption (Equation 3). The ideal value is $100 \%$ which means that after the initiation of crushing (peak crush load) the load will remain the same (mean load). A low percentage is not desirable; because a higher initial force (acceleration) will be transferred to the non-sacrificial structure.

*Corresponding author: Sivakumar Palanivelu, Tel: +32-(0)9-264.33.15, Fax: +32-(0)9-264.35.87 


$$
\begin{gathered}
P_{\text {mean }}=\frac{\int_{0}^{l_{\text {max }}} P(l) d l}{l_{\text {max }}}(\mathrm{kN}) \\
S E A=\frac{\int_{0}^{l_{\text {max }}} P(\mathrm{l}) \mathrm{dl}}{m_{t}}(\mathrm{~kJ} / \mathrm{kg}) \\
\eta_{c}=\frac{P_{\text {mean }}}{P_{\text {max }}} \times 100 \%
\end{gathered}
$$

where $P(l)$ is the instantaneous crushing load corresponding to the instantaneous crushing deformation length $d l ; l_{\max }$ is the maximum or total deformation length $(70 \mathrm{~mm}) ; m_{t}$ is the mass of each composite tube for $70 \mathrm{~mm}$ length; $P_{\max }$ is the peak crush load of each composite tube. The calculated average values (from 4 test specimens) of each composite tube series are given in Table 2.

\subsection{Effect of polyurethane foam on SEA and peak crush load}

The average specific energy absorption of $1 \mathrm{~mm}$ and $2 \mathrm{~mm}$ thickness composite tubes are given in Figure 13(a) and Figure 13(b) respectively. In order to compare the results with empty composite tubes (without polyurethane foam), the results from our previous study [1] are included in the same figure. The nomenclature of the composite tubes without polyurethane foam is very similar to the nomenclature of composite tubes with polyurethane foam; the letter " $\boldsymbol{F}$ " is not included in the name series to represent the tubes without polyurethane foam [1]. The presence of polyurethane foam inside the composite tube significantly improved the stability during the crushing process and subsequent energy absorption for $1 \mathrm{~mm}$ thickness square and hexagonal cross-sectional tubes. The square and hexagonal cross-sectional composite tubes without polyurethane foam showed a catastrophic failure mode [1]. On the contrary, the presence of polyurethane foam inside the composite tubes (for $1 \mathrm{~mm}$ and $2 \mathrm{~mm}$ thickness) significantly reduced the SEA of the remaining geometrical shapes (circular cross sectional, hourglass type - A, hourglass type - B, conical circular type - X and conical circular type - Y). The major reason for the reduction of SEA is a lower mean crush load which was controlled by the corresponding deformation patterns. Figure 15 shows a representative comparison of cut sectional views of crushed tubes. The composite tubes without polyurethane foam showed a clear evidence of circumferential delamination at its mid thickness, lamina bending, axial cracks and fibre fracturing failure modes which attributed to a higher mean crush load and corresponding SEA. However, for the tubes with polyurethane foam the delamination was suppressed after the crushing of the triggering profile and hence, the mean load was controlled by axial cracks, lamina bending and foam compression. This fact is again proved for the circular cross sectional tubes with partially removed polyurethane foam (refer Figure 13(b)).

The effect of polyurethane foam on the peak crush load of each geometrical shape of the composite tubes can be clearly understood from Figure 14(a) and Figure 14(b). The peak crush load of the composite tubes with polyurethane foam was higher than for the tubes without polyurethane foam. Keeping a lower failure load for the inner core member (composite tubes) may attribute to achieve the progressive deformations easily during an explosion event and so the magnitude of the peak load transferred to the non-sacrificial structure can be minimised. Hence, the tubes without polyurethane foam can provide good 
energy absorption values at lower peak crush loads. However, the effect of strain rate on the peak crush loads should be verified for dynamic load cases. Due to the reduced cross section at the crushing end and the absence of a continuous delamination process the peak crush load of the conical circular type - Y with polyurethane foam was lower than without polyurethane foam.

\section{Conclusions}

In this paper, the effect of polyurethane foam-filling on the crushing performance of smallscale composite tubes (nine different shapes with two different thicknesses) has been evaluated. The presence of polyurethane foam has provided an additional wall strengthening and stability to achieve uniform and progressive crushing failure modes for the tubes which failed catastrophically without polyurethane foam. However, it reduced the specific energy absorption significantly for the composite tubes which can already provide progressive and stable failure patterns without polyurethane foam. The reason for the reduction in the specific energy absorption was the difference in the deformation patterns (presence of polyurethane foam prevented the circumferential delamination and subsequent fibre fracturing). Furthermore, the architecture of the composite tubes also played a role (in this study the reinforcement fibres are oriented along the axis of the tube; and so a lower hoop strength is obtained). Hence, before deploying the foam-filling in a composite structure for energy absorption applications one should be aware that any changes in the failure pattern due to foam-filling can alter the crushing performance of the composite structure.

\section{Acknowledgements}

The authors gratefully acknowledge the financial support of the "Fund for Scientific Research” - Flanders (F.W.O) (Grant No: B-07674-03).

\section{References}

[1]. Palanivelu, S., Van Paepegem W., Degrieck J., Kakogiannis D., Van Ackeren J., Van Hemelrijck D., Wastiels J. and Vantomme J., Comparative study of the quasi-static energy absorption of small-scale composite tubes with different geometrical shapes for use in sacrificial cladding structures. Polymer Testing. 29(3): p. 381-396.

[2]. Guruprasad, S. and Mukherjee A., Layered sacrificial claddings under blast loading Part II -- experimental studies. International Journal of Impact Engineering, 2000. 24(9): p. 975-984.

[3]. Hanssen, A. G., Enstock L. and Langseth M., Close-range blast loading of aluminium foam panels. International Journal of Impact Engineering, 2002. 27(6): p. 593-618.

[4]. Arnaud, P. and Hamelin P., Dynamic characterization of structures: A study of energy absorption in composite tubes. Composites Science and Technology, 1998. 58(5): p. 709-715.

[5]. Farely, G. L., Energy absorption of composite materials Journal of Composite Materials, 1983. 17: p. 167.

[6]. Hamada, H., Kameo K., Sakaguchi M., Saito H. and Iwamoto M., Energy-absorption properties of braided composite rods. Composites Science and Technology, 2000. 60(5): p. 723-729.

[7]. Mamalis, A. G., Manolakos D. E., Demosthenous G. A. and Ioannidis M. B., Analytical and experimental approach to damage and residual strength of fibreglass

*Corresponding author: Sivakumar Palanivelu, Tel: +32-(0)9-264.33.15, Fax: +32-(0)9-264.35.87 
composite automotive frame rails during manufacturing. Composite Structures, 1995. 32(1-4): p. 325-330.

[8]. Thronton, P. H., Energy absorption in composite structures. Journal of Composite Materials, 1979. 13(247).

[9]. Hamada, H. and Ramakrishna S., Scaling effects in the energy absorption of carbonfiber/PEEK composite tubes. Composites Science and Technology, 1995. 55(3): p. 211-221.

[10]. Aktay, L., Toksoy A. K. and Güden M., Quasi-static axial crushing of extruded polystyrene foam-filled thin-walled aluminum tubes: Experimental and numerical analysis. Materials \& Design, 2006. 27(7): p. 556-565.

[11]. Hall, I. W., Guden M. and Claar T. D., Transverse and longitudinal crushing of aluminum-foam filled tubes. Scripta Materialia, 2002. 46(7): p. 513-518.

[12]. Toksoy, A. K. and Güden M., The strengthening effect of polystyrene foam filling in aluminum thin-walled cylindrical tubes. Thin-Walled Structures. 43(2): p. 333-350.

[13]. Zarei, H. R. and Kröger M., Optimization of the foam-filled aluminum tubes for crush box application. Thin-Walled Structures, 2008. 46(2): p. 214-221.

[14]. Hanssen, A. G., Langseth M. and Hopperstad O. S., Static and dynamic crushing of circular aluminium extrusions with aluminium foam filler. International Journal of Impact Engineering, 2000. 24(5): p. 475-507.

[15]. Babbage, J. M. and Mallick P. K., Static axial crush performance of unfilled and foam-filled aluminum-composite hybrid tubes. Composite Structures, 2005. 70(2): p. 177-184.

[16]. Guden, M., Yüksel S., Tasdemirci A. and Tanoglu M., Effect of aluminum closed-cell foam filling on the quasi-static axial crush performance of glass fiber reinforced polyester composite and aluminum/composite hybrid tubes. Composite Structures, 2007. 81(4): p. 480-490.

[17]. Harte, A.-M., Fleck N. A. and Ashby M. F., Energy absorption of foam-filled circular tubes with braided composite walls. European Journal of Mechanics - A/Solids, 2000. 19(1): p. 31-50.

[18]. Mamalis, A. G., Manolakos D. E., Ioannidis M. B., Chronopoulos D. G. and Kostazos P. K., On the crashworthiness of composite rectangular thin-walled tubes internally reinforced with aluminium or polymeric foams: Experimental and numerical simulation. Composite Structures, 2009. 89(3): p. 416-423.

[19]. Palanivelu, S., Van Paepegem W., Degrieck J., Van Ackeren J., Kakogiannis D., Van Hemelrijck D., Wastiels J. and Vantomme J., Experimental study on the axial crushing behaviour of pultruded composite tubes. Polymer Testing. 29(2): p. 224-234.

[20]. Mamalis, A. G., Manolakos D. E., Demosthenous G. A. and Ioannidis M. B., Energy absorption capability of fibreglass composite square frusta subjected to static and dynamic axial collapse. Thin-Walled Structures, 1996. 25(4): p. 269-295.

[21]. Solaimurugan, S. and Velmurugan R., Progressive crushing of stitched glass/polyester composite cylindrical shells. Composites Science and Technology, 2007. 67(3-4): p. 422-437.

[22]. Farely, G. L., Effect of specimen geometry on the energy absorption of composite materials. Journal of Composite Materials, 1986. 20: p. 390.

[23]. W.Hyer, M. R. S. A. M., Static energy absorption capacity of graphite-epoxy tubes. Journal of Composite Materials, 2000. 35. 


\section{FIGURES AND CAPTIONS:}

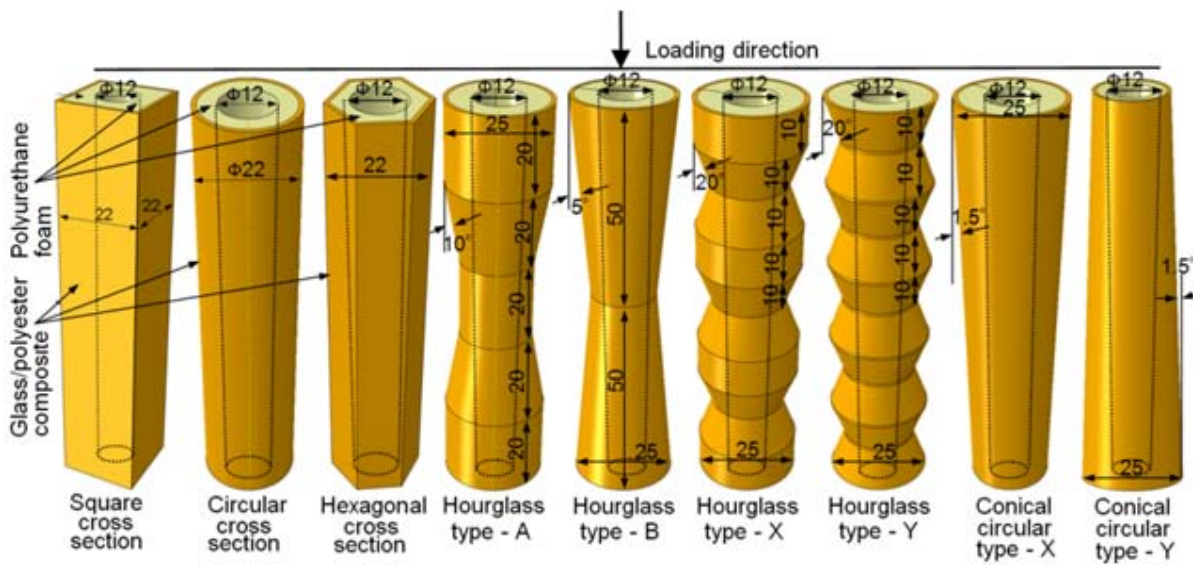

(a) Dimensional details of the composite tubes.

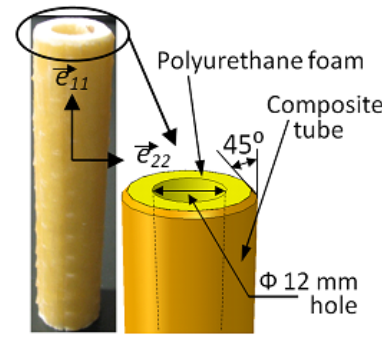

(b) Triggering details.

Figure 1: (a) Different geometrical shapes of the composite tubes (1mm thickness) and their dimensions considered for the study. (b) Details of triggering.

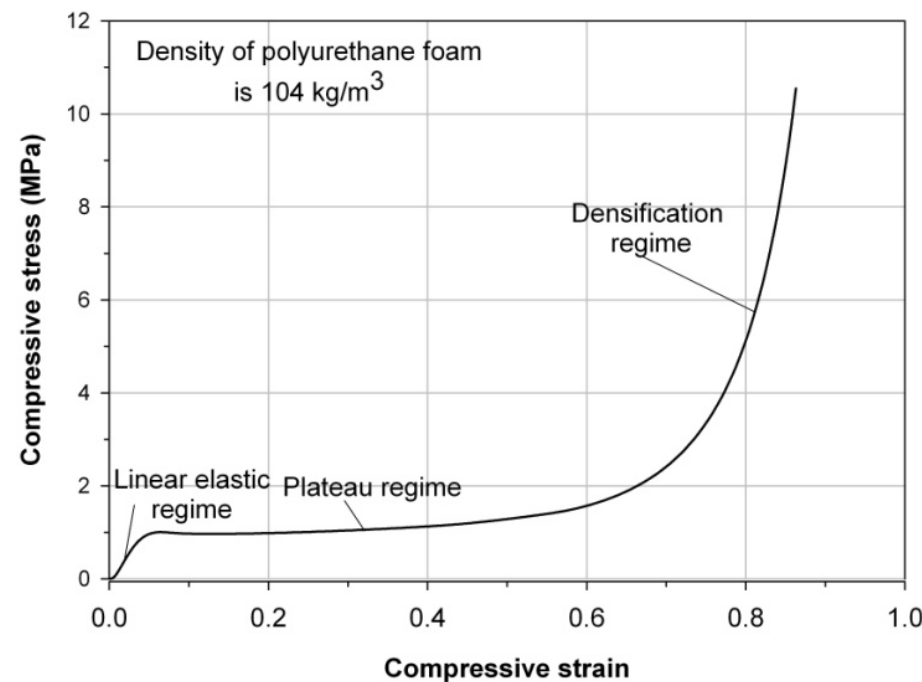

Figure 2: Compressive behaviour of polyurethane foam. 

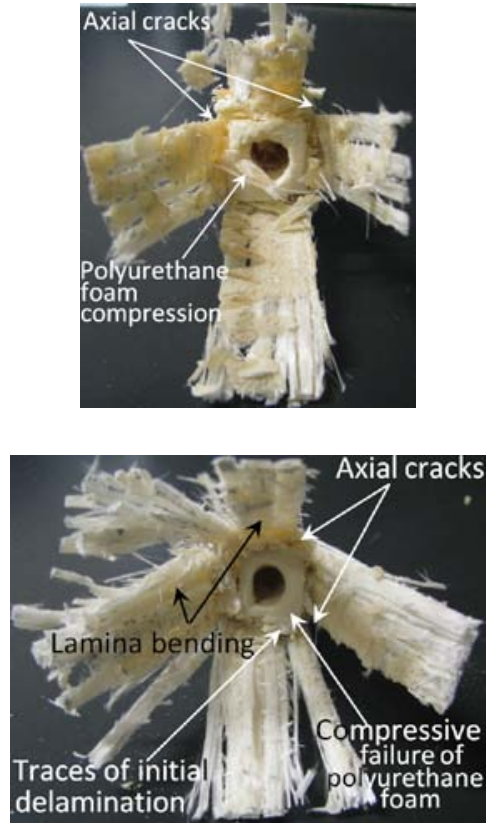

(a) Final deformation patterns (top - SSF; bottom - SDF)
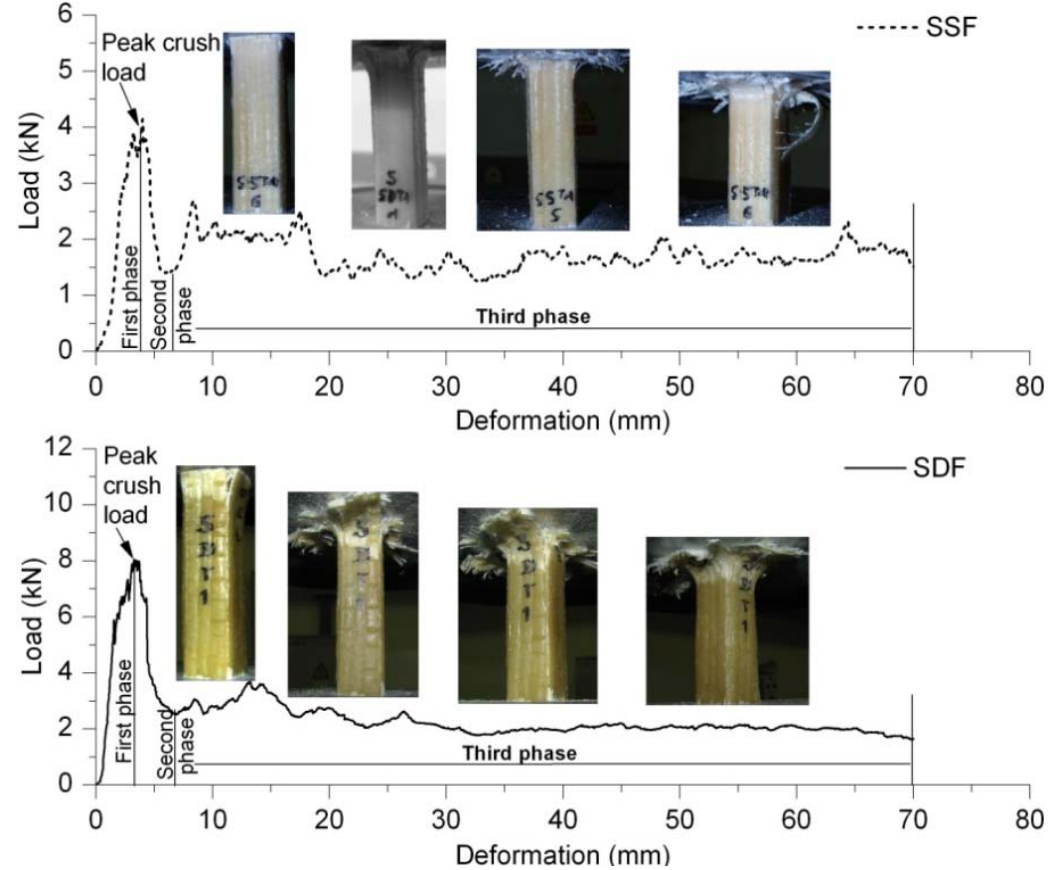

(b) Load - deformation histories (top -SSF; bottom - SDF).

Figure 3: Deformation patterns and the crushing performance of the square cross sectional composite tubes filled with polyurethane foam.
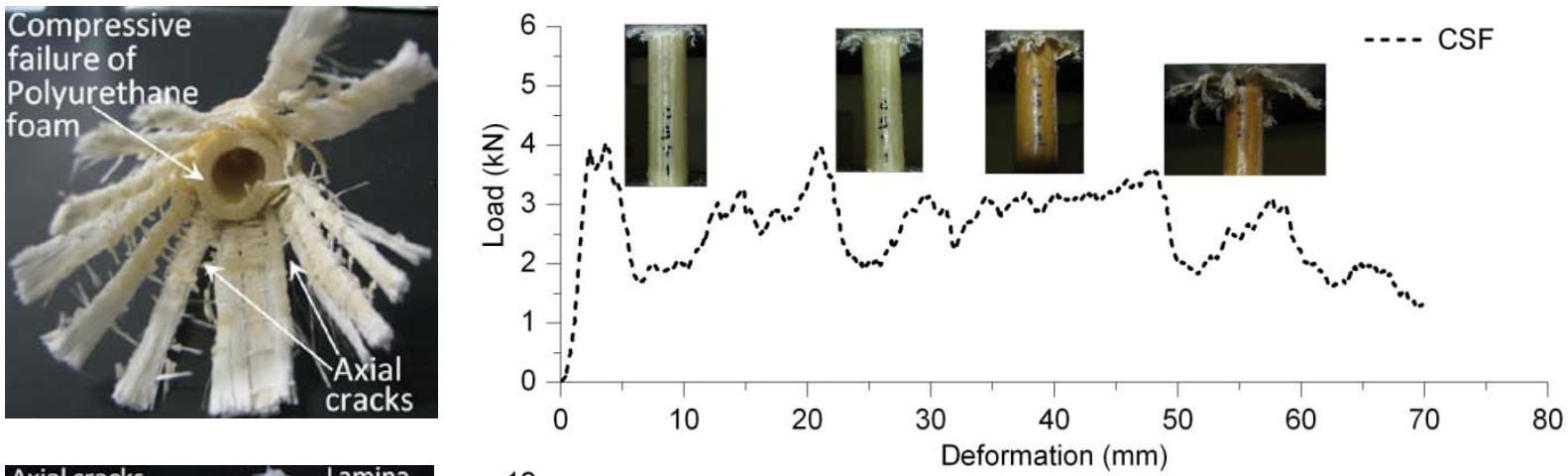

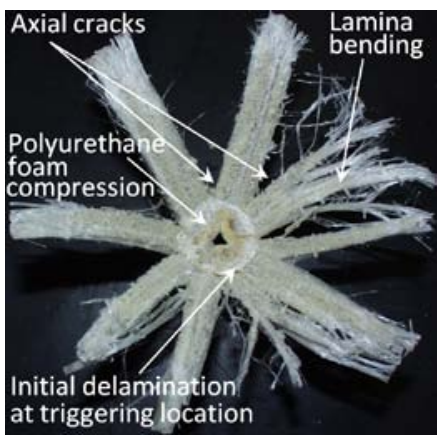

(a) Final deformation patterns (top - CSF; bottom - CDF).

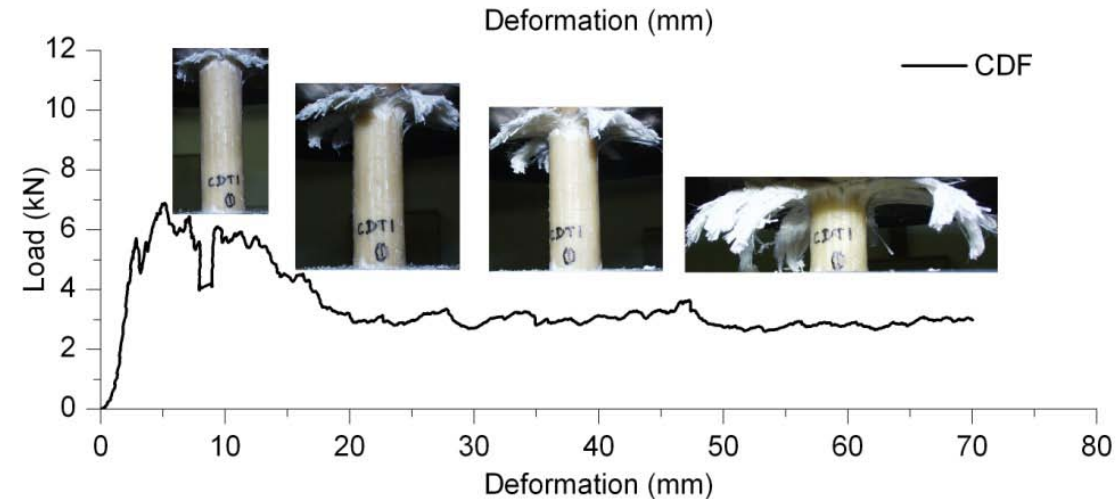

(b) Load - deformation histories (top - CSF; bottom - CDF).

Figure 4: Deformation patterns and the crushing performance of the circular cross sectional composite tubes filled with polyurethane foam. 

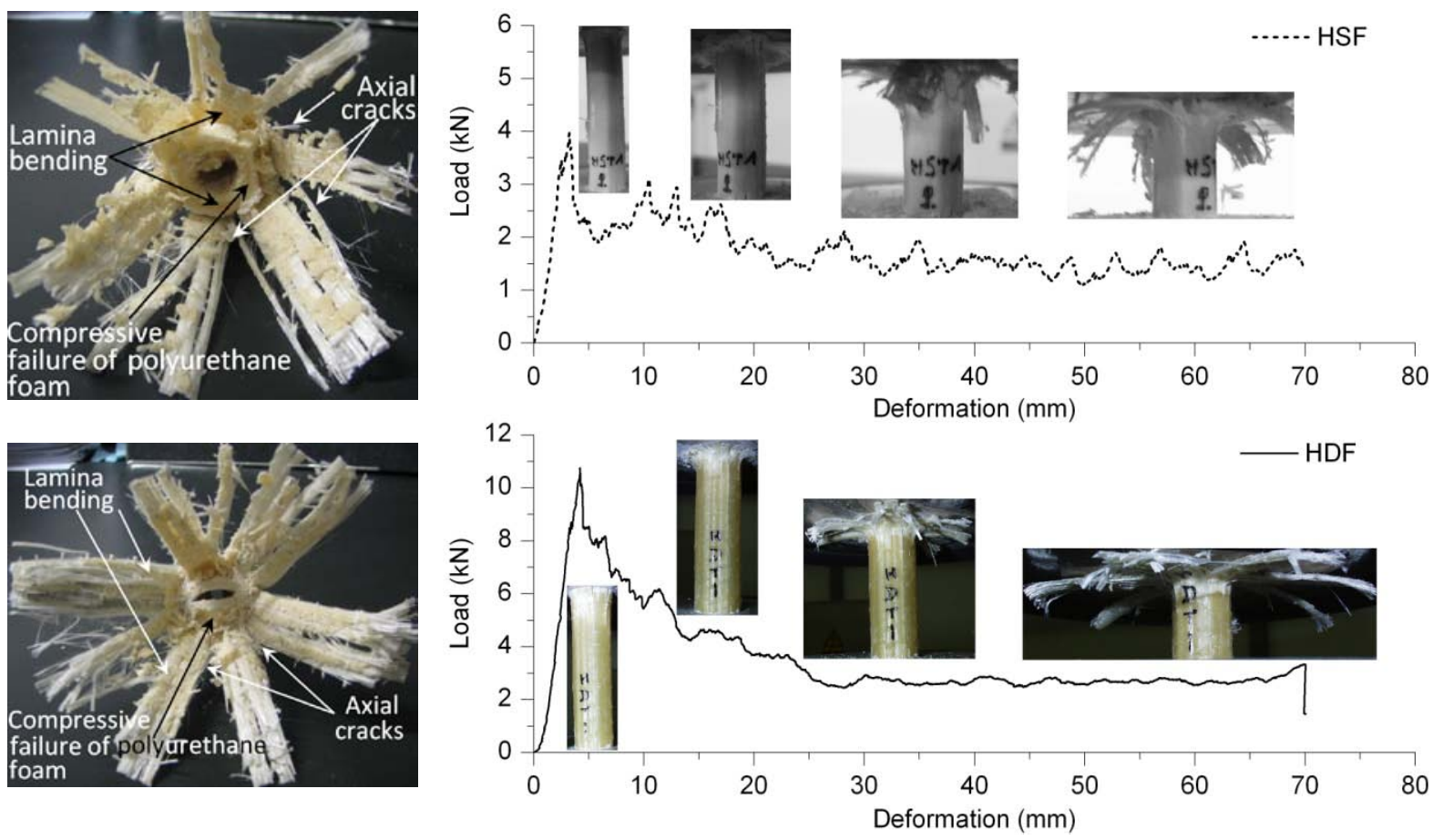

(a) Final deformation patterns (top - HSF; bottom - HDF).

(b) Load - deformation histories (top - HSF; bottom - HDF).

Figure 5: Deformation patterns and the crushing performance of the hexagonal cross sectional composite tubes filled with polyurethane foam.
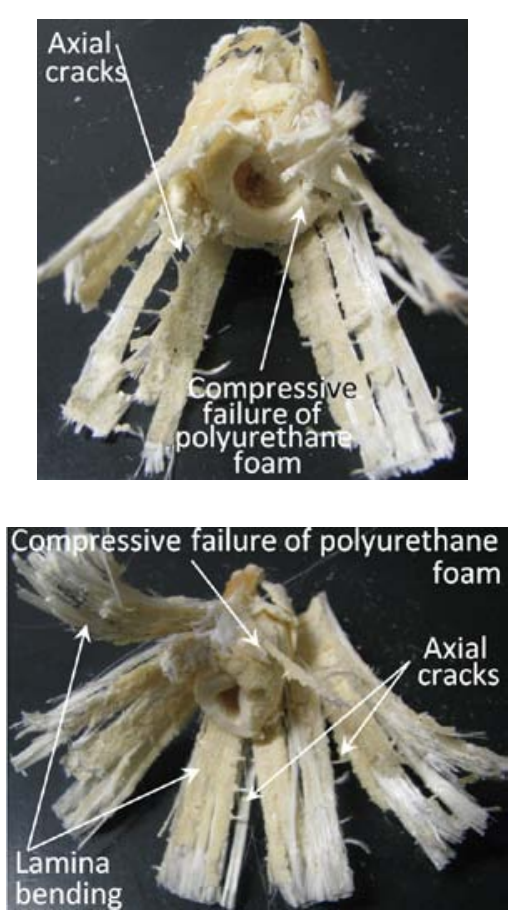

(a) Final deformation patterns (top - HASF; bottom - HADF).
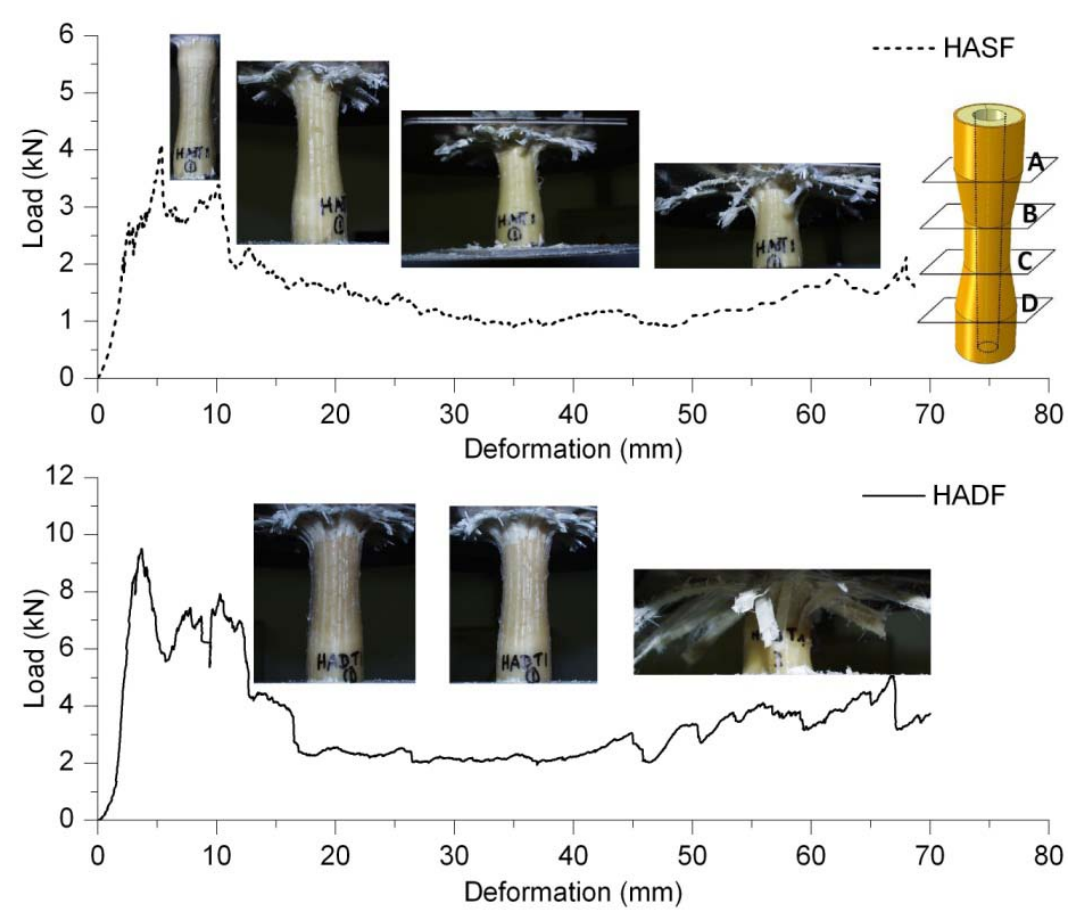

(b) Load - deformation histories (top - HASF; bottom - HADF)

Figure 6: Deformation patterns and the crushing performance of the hourglass type - A composite tubes filled with polyurethane foam.

*Corresponding author: Sivakumar Palanivelu, Tel: +32-(0)9-264.33.15, Fax: +32-(0)9-264.35.87 

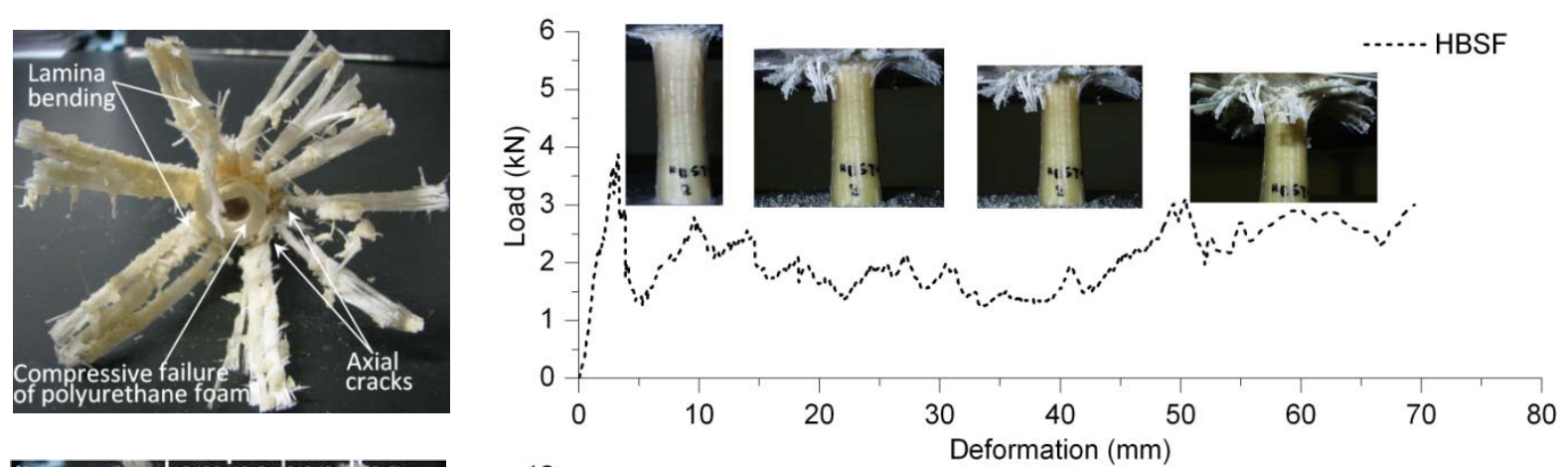

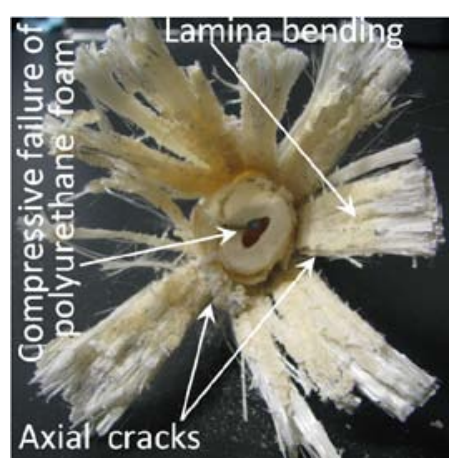

(a) Final deformation patterns (top - HBSF; bottom - HBDF).

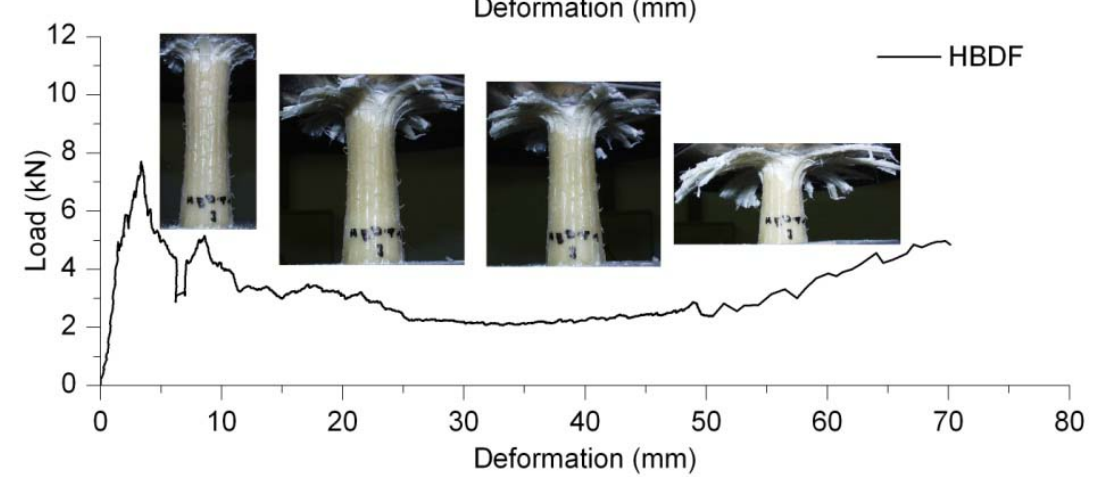

(b) Load - deformation histories (top - HBSF; bottom - HBDF).

Figure 7: Deformation patterns and the crushing performance of the hourglass type - B composite tubes filled with polyurethane foam.
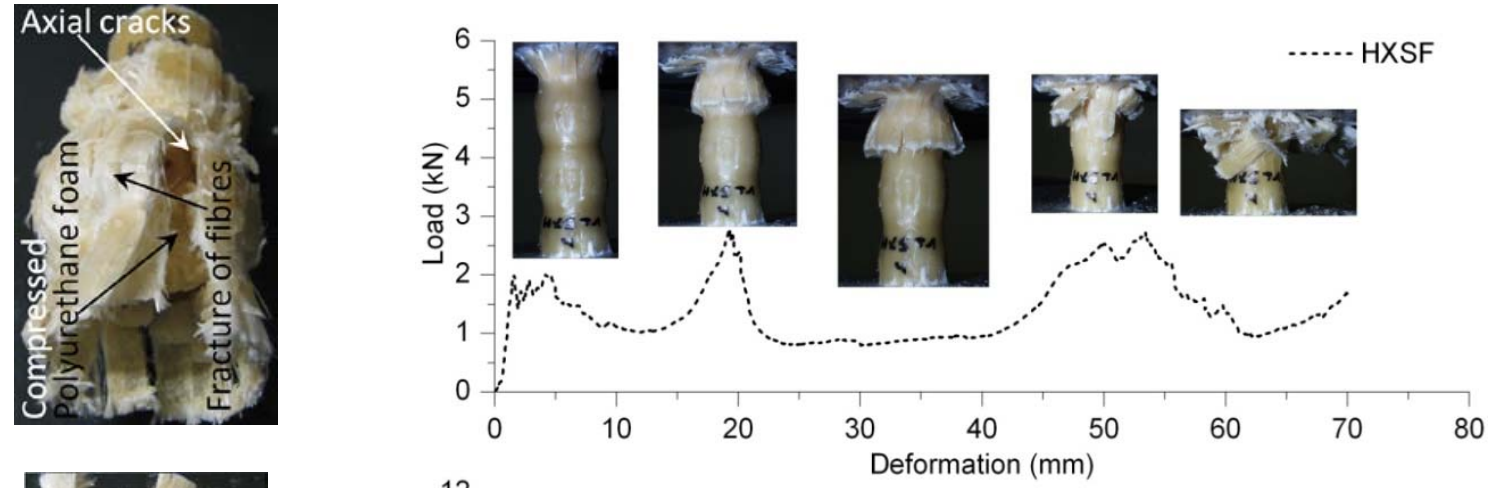

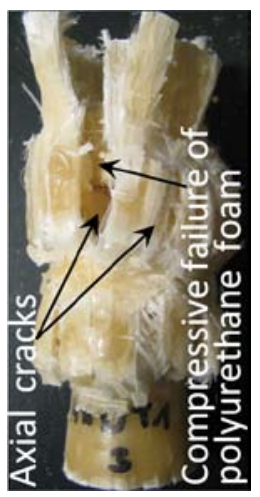

(a) Final deformation patterns (top - HXSF; bottom - HXDF).

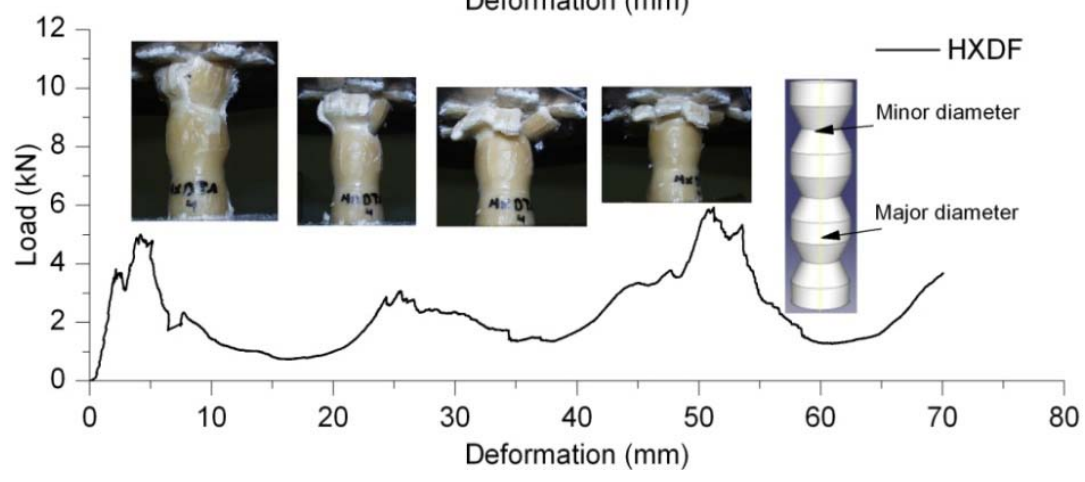

(b) Load - deformation histories (top - HXSF; bottom - HXDF).

Figure 8: Deformation patterns and the crushing performance of the hourglass type - $\mathrm{X}$ composite tubes filled with polyurethane foam.

*Corresponding author: Sivakumar Palanivelu, Tel: +32-(0)9-264.33.15, Fax: +32-(0)9-264.35.87 

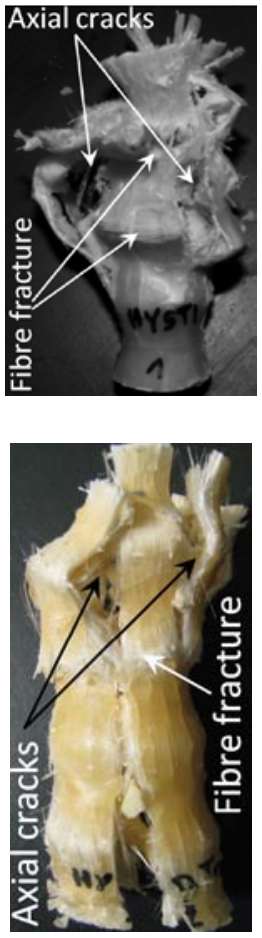

(a) Final deformation patterns (top - HYSF; bottom - HYDF)
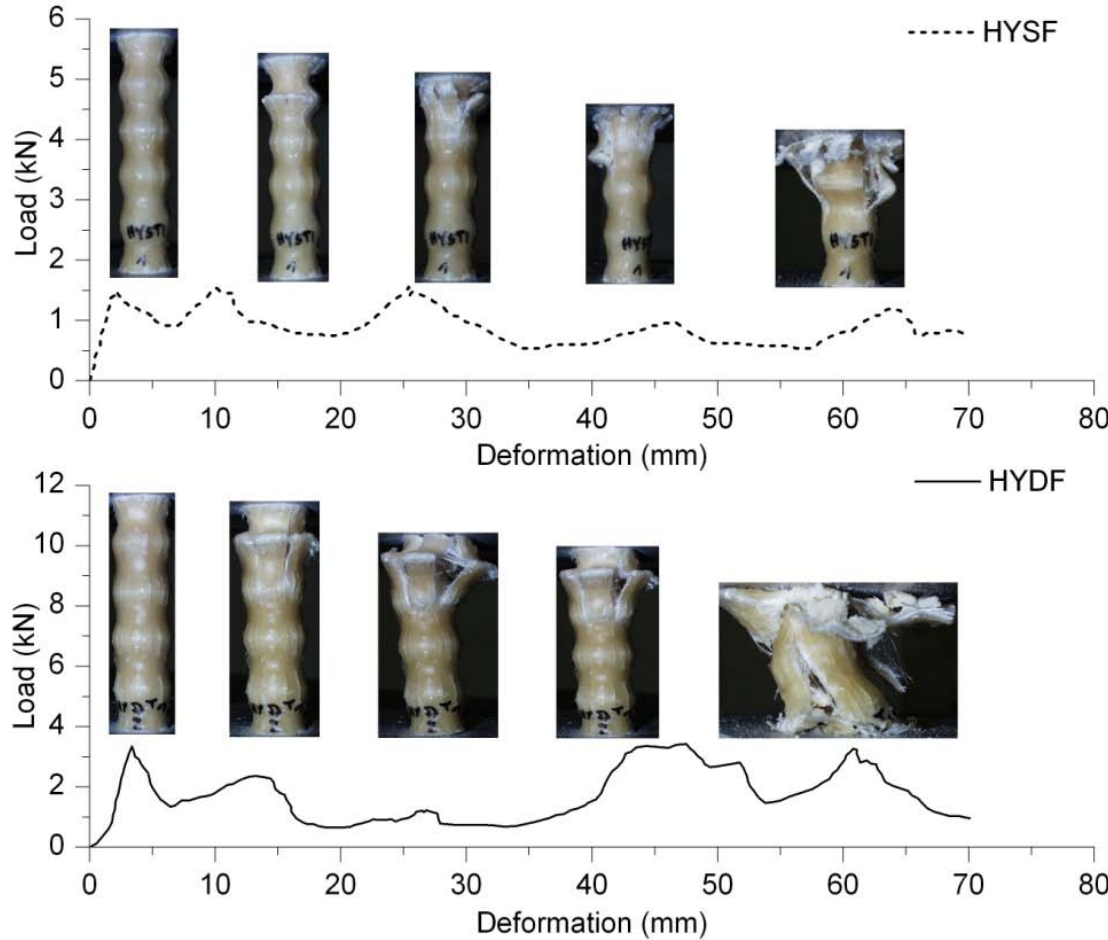

(b) Load - deformation histories (top - HYSF; bottom - HYDF).

Figure 9: Deformation patterns and the crushing performance of the hourglass type - Y composite tubes filled with polyurethane foam.
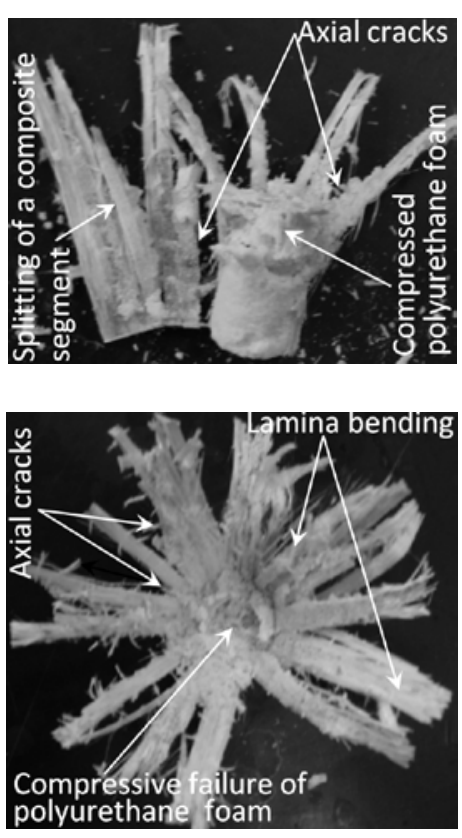

(a) Final deformation patterns (top - CXSF; bottom - CXDF).
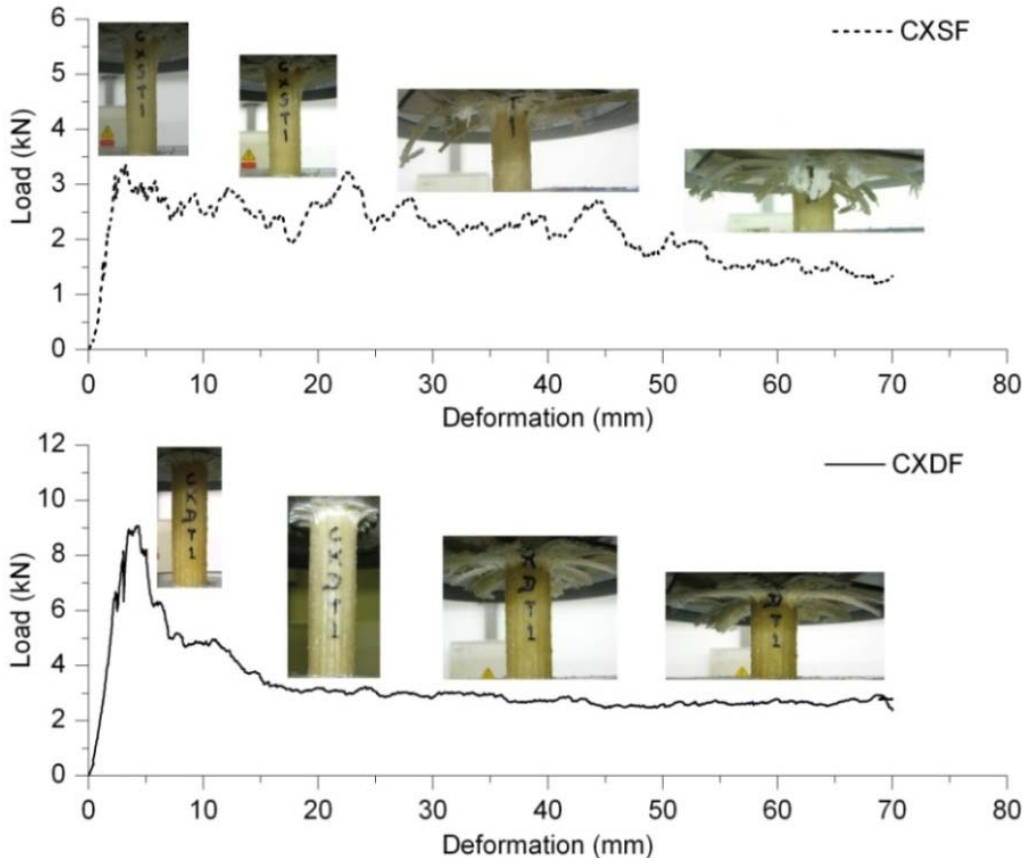

(b) Load - deformation histories (top - CXSF; bottom - CXDF).

Figure 10: Deformation patterns and the crushing performance of the conical circular type $\mathrm{X}$ composite tubes filled with polyurethane foam. 

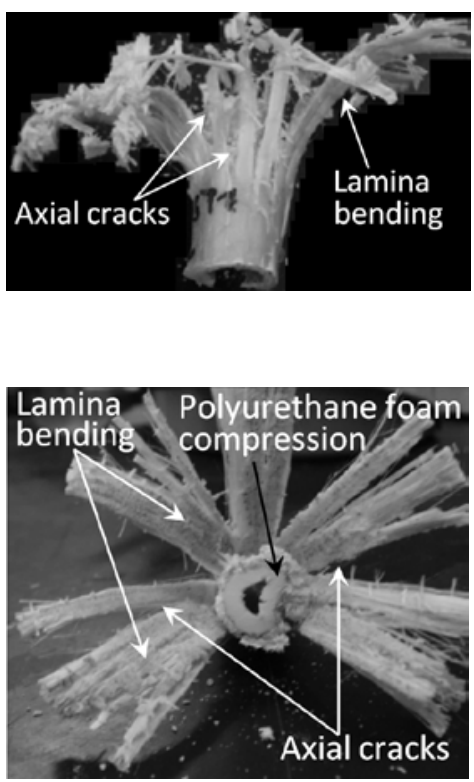

(a) Final deformation patterns (top - CYSF; bottom - CYDF).
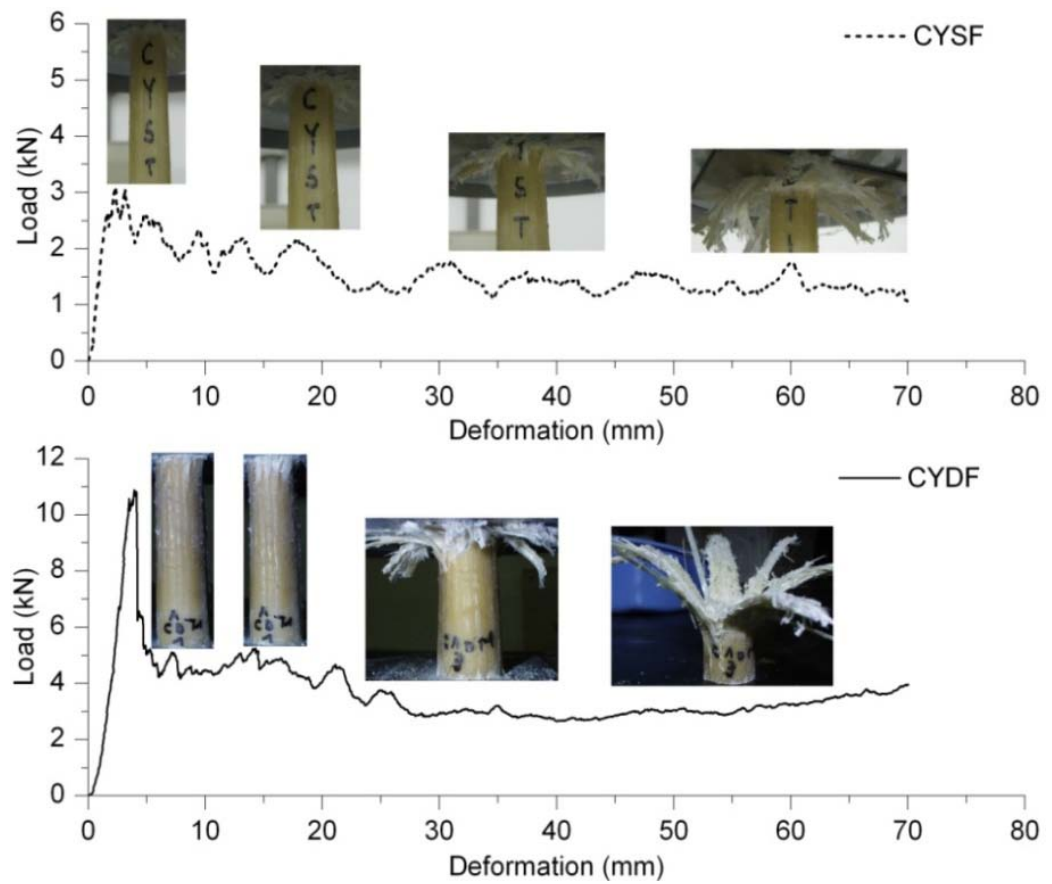

(b) Load - deformation histories (top - CYSF; bottom - CYDF).

Figure 11: Deformation patterns and the crushing performance of the conical circular type Y composite tubes filled with polyurethane foam.
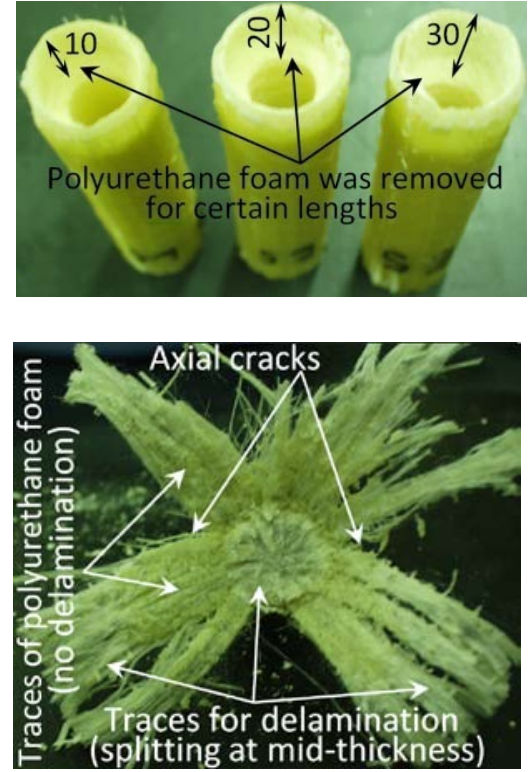

(a) top - test specimens; bottom - final deformation pattern.

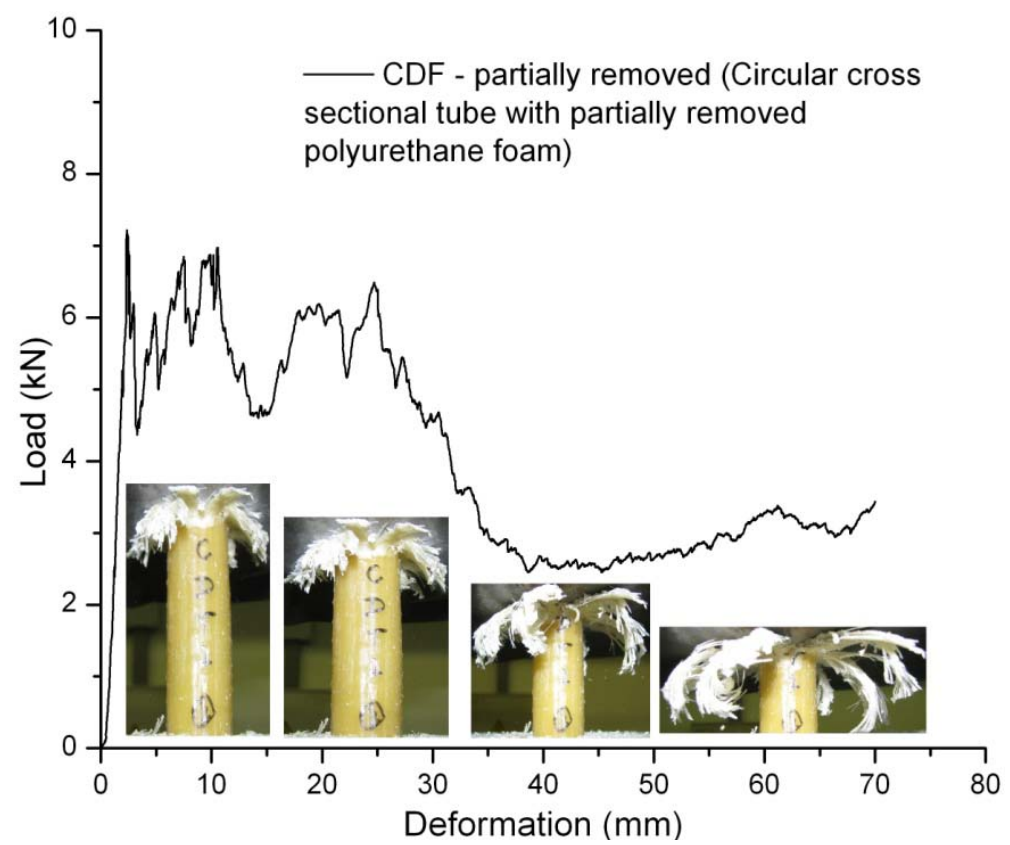

(b) Load - deformation history.

Figure 12: Details of test specimen, deformation pattern and the corresponding crushing performance of circular cross sectional tubes with partially removed polyurethane foam (30 $\mathrm{mm}$ foam removal case). 


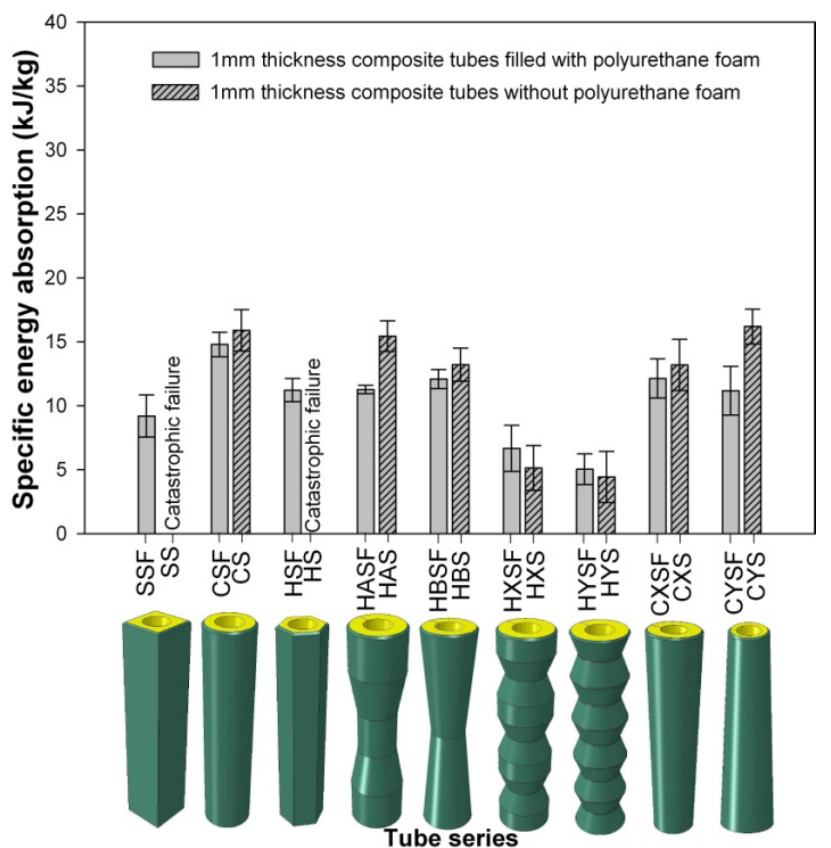

(a) For $1 \mathrm{~mm}$ thickness composite tubes.

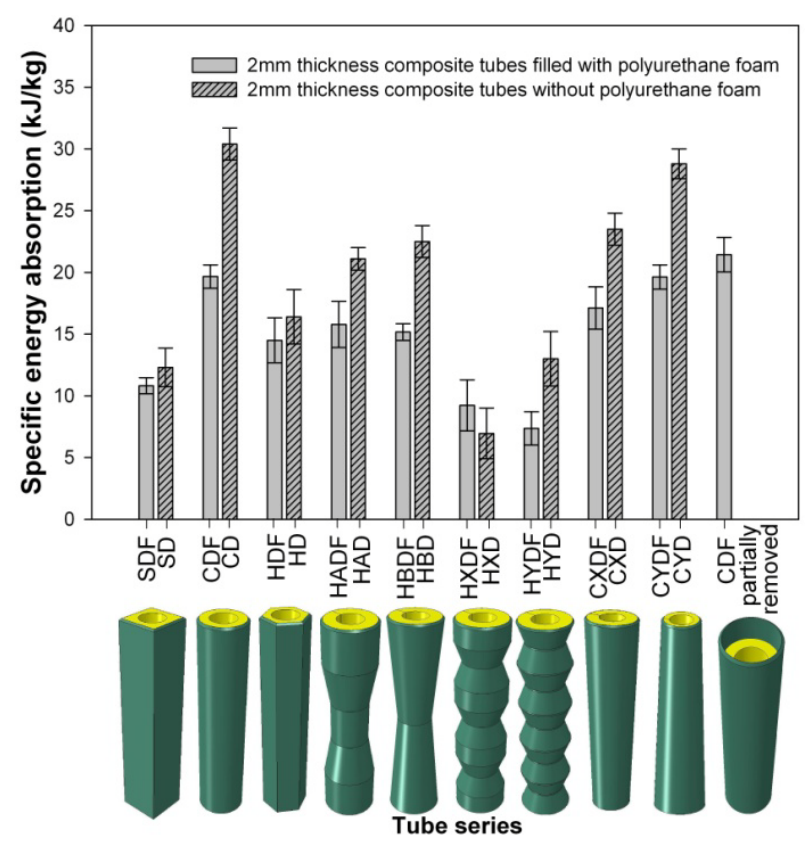

(b) For $2 \mathrm{~mm}$ thickness composite tubes.

Figure 13: Comparison of the specific energy absorption for (1 $\mathrm{mm}$ and $2 \mathrm{~mm}$ thickness) composite tubes series with and without polyurethane foam (error bar indicates standard deviation).

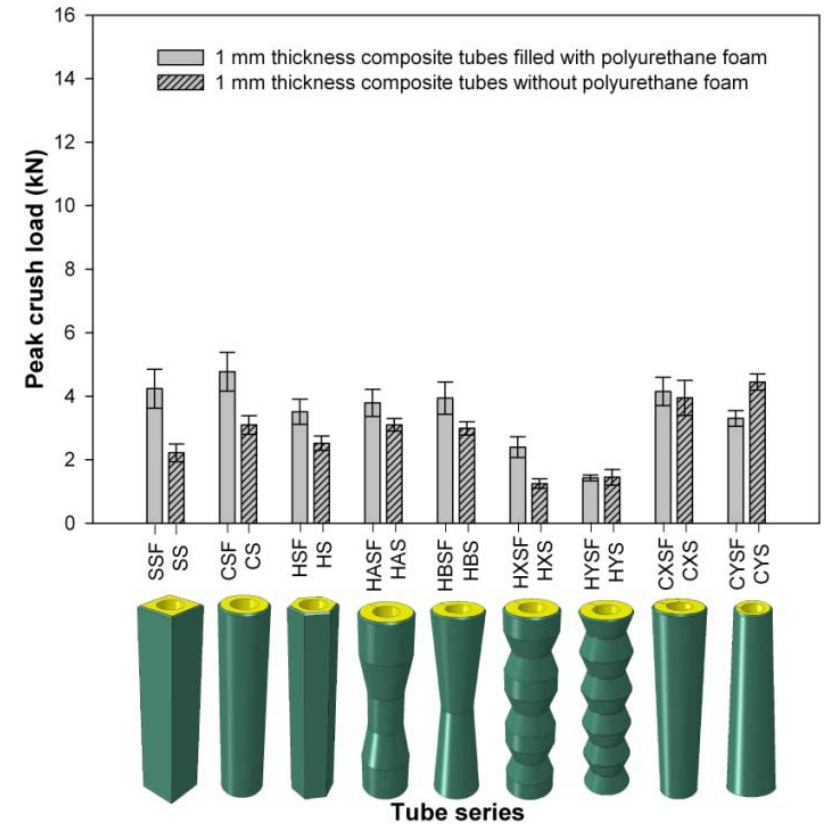

(a) For $1 \mathrm{~mm}$ thickness composite tubes.

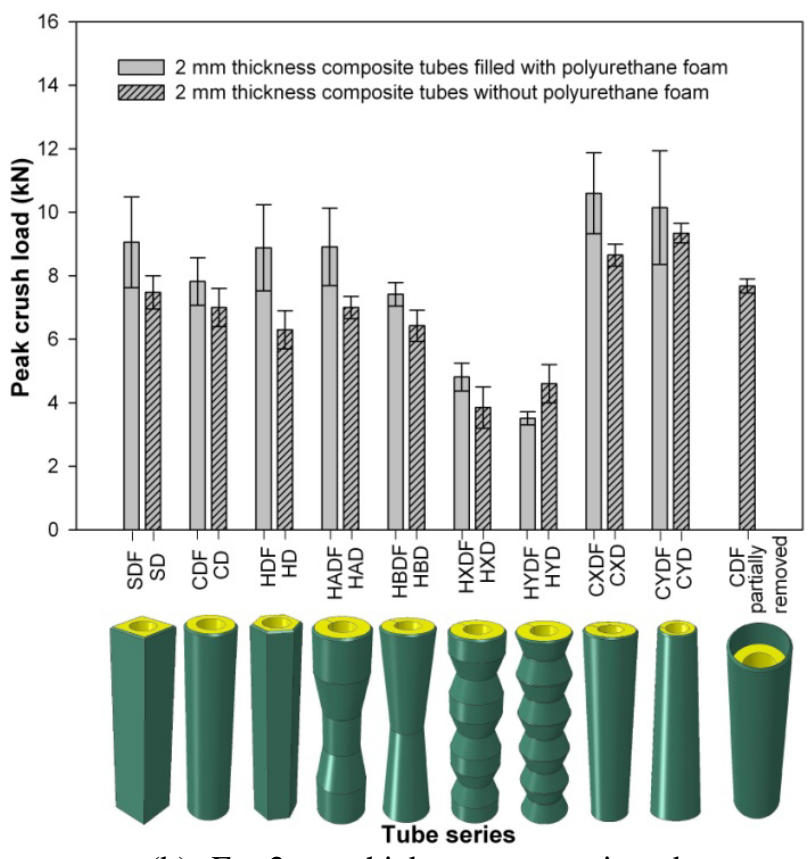

(b) For $2 \mathrm{~mm}$ thickness composite tubes.

Figure 14: Comparison of the peak crush load for (1 $\mathrm{mm}$ and $2 \mathrm{~mm}$ thickness) composite tubes series with and without polyurethane foam (error bar indicates standard deviation). 


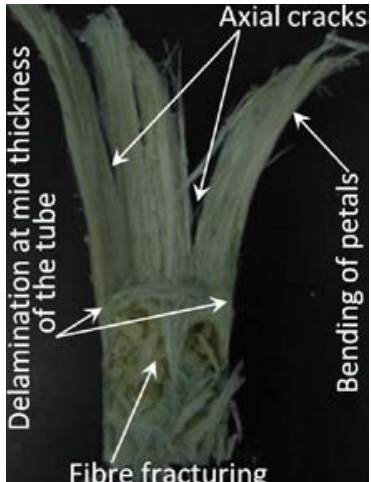

(a)

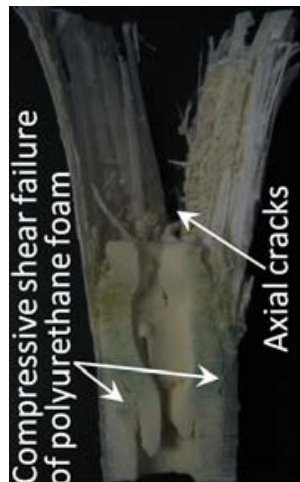

(b)

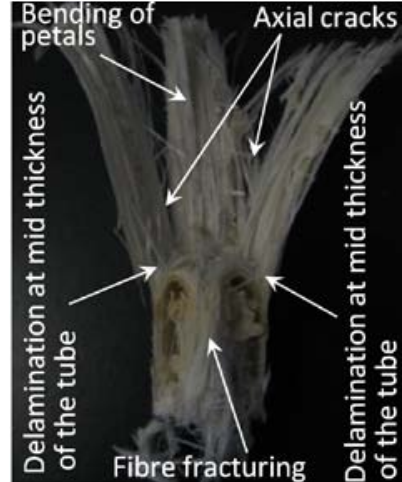

(c)

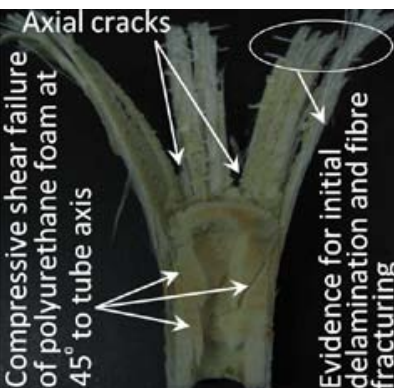

(d)

Figure 15: Comparison of longitudinal cut sections of composite tubes: (a) 1mm thickness tube without polyurethane foam. (b) $1 \mathrm{~mm}$ thickness tube filled with polyurethane foam. (c) 2 mm thickness tube without polyurethane foam. (d) $2 \mathrm{~mm}$ thickness tube filled with polyurethane foam. 
TABLES:

Table 1: Nomenclature, geometry and dimensional details of the composite tube series.

\begin{tabular}{|c|c|c|c|c|c|}
\hline $\begin{array}{l}\text { S. } \\
\text { No }\end{array}$ & $\begin{array}{l}\text { Tube } \\
\text { series }\end{array}$ & $\begin{array}{c}\text { Cross section / Geometry of the composite } \\
\text { tube }\end{array}$ & $\begin{array}{l}\text { t/D or t/W ratio } \\
\text { (excluding } \\
\text { polyurethane foam) }\end{array}$ & $\begin{array}{l}\text { Length } \\
\text { (mm) }\end{array}$ & $\begin{array}{c}\rho_{\text {linear }}(\mathrm{g} / \mathrm{mm}) \\
\text { (including } \\
\text { polyurethane foam) }\end{array}$ \\
\hline \multicolumn{6}{|c|}{ Wall thickness of the composite tube $=1 \mathrm{~mm}$} \\
\hline 1 & SSF & Square cross sectional tubes & 0.045 & \multirow{9}{*}{100} & 0.1537 \\
\hline 2 & CSF & Circular cross sectional tubes & 0.045 & & 0.1454 \\
\hline 3 & HSF & Hexagonal cross sectional tubes & 0.045 & & 0.1317 \\
\hline 4 & HASF & Hourglass type - A tube & 0.043 & & 0.1293 \\
\hline 5 & HBSF & Hourglass type - B tubes & 0.045 & & 0.1346 \\
\hline 6 & $H X S F$ & Hourglass type - X tubes & 0.043 & & 0.1440 \\
\hline 7 & HYSF & Hourglass type - Y tubes & 0.046 & & 0.1366 \\
\hline 8 & CXSF & Conical circular type - X tubes & 0.045 & & 0.1336 \\
\hline 9 & CYSF & Conical circular type - Y tubes & 0.045 & & 0.1172 \\
\hline \multicolumn{6}{|c|}{ Wall thickness of the composite tube $=2 \mathrm{~mm}$} \\
\hline 10 & SDF & Square cross sectional tubes & 0.083 & \multirow{10}{*}{100} & 0.2376 \\
\hline 11 & $C D F$ & Circular cross sectional tubes & 0.083 & & 0.1775 \\
\hline 12 & HDF & Hexagonal cross sectional tubes & 0.083 & & 0.2117 \\
\hline 13 & HADF & Hourglass type - A tubes & 0.080 & & 0.2093 \\
\hline 14 & $H B D F$ & Hourglass type - B tubes & 0.083 & & 0.2460 \\
\hline 15 & HXDF & Hourglass type - X tubes & 0.080 & & 0.2117 \\
\hline 16 & HYDF & Hourglass type - Y tubes & 0.084 & & 0.1994 \\
\hline 17 & $C X D F$ & Conical circular type - X tubes & 0.083 & & 0.1990 \\
\hline 18 & $C Y D F$ & Conical circular type - Y tubes & 0.083 & & 0.2040 \\
\hline 19 & $\begin{array}{l}\text { CDF- } \\
\text { partially } \\
\text { removed }\end{array}$ & $\begin{array}{l}\text { Circular cross sectional tubes with partially } \\
\text { removed ( } 30 \mathrm{~mm} \text { length) polyurethane } \\
\text { foam }\end{array}$ & 0.083 & & 0.1729 \\
\hline
\end{tabular}

(Example of the nomenclature of the circular cross sectional composite tubes: (i) $\boldsymbol{C S F}$ - Circular cross section, Single ply (1 mm thick), $\boldsymbol{F}$ - polyurethane $\boldsymbol{F}$ oam filled; (ii) $\boldsymbol{C D F}$ - Circular cross section, Double plies (2 mm thick), $\boldsymbol{F}$ - polyurethane $\boldsymbol{F}$ oam filled)

Table 2: Summary of the average crushing parameters of all composite tube series.

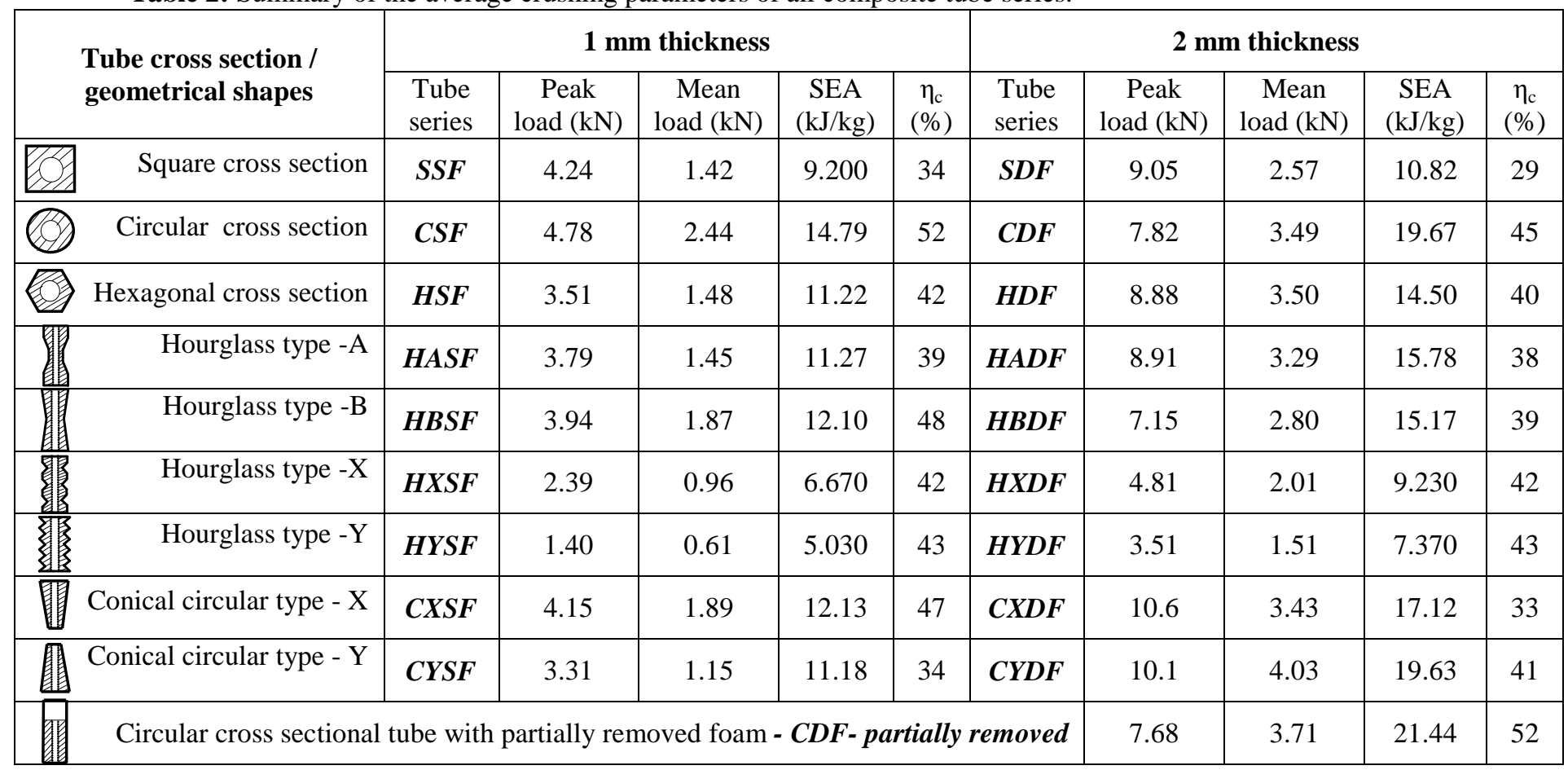

